\title{
Docencia en pandemia y apuntes para posibles futuros educativos
}

Shirley Vallejo Tapia ${ }^{1}$

\begin{abstract}
Resumen:
Este ensayo comunica algunas reflexiones sobre la educación, sus sujetos y el currículo, a partir de la condición humana actual, en una educación pensada en términos colectivos y el currículum, en tanto registro de las disputas por posicionamiento de discursos y saberes. Las ideas que aquí se están construyendo surgen a partir de entrevistas dialógico-narrativas con docentes del sistema público de educación básica y media superior de Quito, Ecuador. Encuentros realizados dentro de una investigación con paradigma cualitativo, asentada en el giro cultural y el enfoque narrativo para entender la docencia y sus saberes. Las conversaciones fueron sobre la escuela y la docencia, en su condición actual de traslado a la virtualidad o el espacio doméstico, y sobre cómo la pandemia por Covid coloca a la sociedad de frente a los problemas vitales del mundo que estamos construyendo. La indagación se realiza dentro del programa de Maestría en Pedagogía de la Universidad Nacional Autónoma de México y el Consejo Nacional de Ciencia y Tecnología. Las consideraciones que aquí se exponen surgen también de los diálogos en espacios académicos del programa de posgrado como el Seminario de "Saberes Pedagógicos y Justicia Educativa". Algunos autores presentes son Flavia Terigi, Ana Salmerón, Maarten Simons, y Jan Masschelein.
\end{abstract}

\author{
Palabras clave: \\ Educación. Docencia. Pandemia. Currículo. Sujetos.
}

\section{Ensino na pandemia e notas para possíveis futuros educacionais} Resumo:

Este artigo apresenta algumas reflexões sobre a educação, professores, estudantes, e o currículo escolar, a partir da condição humana atual. Numa educação pensada em termos coletivos, e o currículo enquanto registro de disputas por posicionamentos de discursos e saberes. As ideias que aqui se constroem surgem de entrevistas narrativas-dialógicas com professores da rede pública de ensino fundamental e médio de Quito, Equador. Conversas realizadas no âmbito de uma pesquisa de paradigma qualitativo, a partir da abordagem cultural e enfoque narrativo para compreender a docência e seus saberes. Os diálogos abordaram a escola e a docência, em sua condição atual de

1 Candidata a maestra en pedagogía, por el Programa de Posgrado en Pedagogía de la Universidad Nacional Autónoma de México. E-mail: svt1722@gmail.com / svallejo@politicas.unam.mx ORCID iD: https://orcid.org/0000-0002-1033-3074 
mudança para o mundo virtual e ou espaço doméstico, e sobre como a pandemia pela COVID-19 coloca a sociedade diante dos problemas vitais do mundo que estamos construindo. A pesquisa é realizada no âmbito do programa de Mestrado em Pedagogia da Universidade Nacional Autônoma do México e do Conselho Nacional de Ciência e Tecnologia. As considerações aqui apresentadas decorrem também dos diálogos nos espaços acadêmicos do programa de pós-graduação, como o Seminário "Conhecimentos Pedagógicos e Justiça Educacional". Alguns autores presentes são Flavia Terigi, Ana Salmerón, Maarten Simons e Jan Masschelein.

Palavras-chave:

Educação. Docência. Pandemia. Currículo.

\section{Teaching in pandemic and notes for possible educational futures}

\section{Abstract:}

This paper communicates some reflections about education, teachers, and students based on the current human condition, the curriculum, and education as collective. The curriculum is understood here as disputes register over the positioning of the discourses and knowledge. The ideas of this paper emerge from dialogical narrative interviews with teachers from Quito, Ecuador. Those conversations were made inside of a qualitative study with a cultural and narrative approach. The objective was comprehending the teachers' knowledge. These talks were about school, teaching virtually and how the Covid and quarantine situation places the society in front of other problems of the ongoing world. The inquiry is supported by the Pedagogy Postgraduate Program of the National Autonomous University of Mexico and the Science and Technology National Council. The notions that are exposed in that text were developed from dialogues in academic spaces of the Postgraduate Program like the "Pedagogic Knowledge and Educative Justice Seminary." Some authors quoted are Flavia Terigi, Ana Salmerón, Maarten Simons, and Jan Masschelein.

Keywords:

Education. Teaching. Students. Pandemic. Curriculum.

\section{Introducción}

Este artículo es un recorte de una investigación donde se han entrevistado a más de una decena de docentes. Aquí se presenta una experiencia en particular que contribuye a una búsqueda por proponer sentidos y debatir sobre el futuro de la escuela, los docentes y los estudiantes. Por ello pone a discusión algunas reflexiones, surgidas a partir de pensar la docencia de educación básica y media en el contexto de pandemia, en la que la educación escolar fue trasladada obligatoriamente a escenarios virtuales o domésticos donde los docentes se mantienen procurando la escolaridad de los niños.

\section{Prácticas docentes que construyen sentidos colectivos}

En el transcurso de una serie de entrevistas dialógicas con un docente de Lengua y Literatura del nivel de media superior hablamos sobre su práctica de enseñanza en el contexto de pandemia por COVID, en su escenario físico y social: una escuela del sistema educativo público de Quito. El profesor en un momento señaló que no quería que ni él ni sus alumnos "perdieran la cabeza" y por ello convocó, de manera no obligatoria, a los estudiantes a reunirse por una plataforma de 
videollamadas, para leer y conversar sobre una pieza literaria o audiovisual, cada martes y jueves por un lapso de noventa minutos en cada encuentro. (Esto en vista de que las clases virtuales no fueron la modalidad adoptada por esta escuela ya que no se tenía certeza de la infraestructura tecnológica de los estudiantes en sus casas). ${ }^{2}$ Para este maestro el sentido de la actividad es reunirse, una práctica simple pero fundamental, y vital en una temporalidad y territorialidad marcada por la reclusión al espacio doméstico, y el éxodo a la virtualidad en los casos menos desafortunados.

La frase "No perder la cabeza" fue el puente para ingresar a las formas en que los docentes están construyendo sentidos y significados en el contexto de escuela desplazada hacia la virtualidad ${ }^{3}$. Un acceso a comprender cómo están narrando (se) en y sobre esta coyuntura. La propuesta del docente habla de la importancia que para él tiene el soporte que provee el tejido social ${ }^{4}$, los vínculos sociales construidos a través de la escuela. Esos lazos que generan pertenencia en un grupo social mucho más amplio que la familia y los amigos.

Este texto surge de preguntas fundamentales que se hacen los docentes tras este proceso de dislocación ${ }^{5,6}$ : La pregunta es ¿Qué es lo que importa?, ¿qué se requiere para reconstituir lo común? ¿qué nuevos sentidos se pueden inscribir? La convocatoria del docente es el llamado a estar todos en torno a algo, es hacer común-idad, en este caso alrededor de un poema para hablar del mismo. Acción que todos los días se realiza en el espacio áulico y que hoy se dificulta. El docente sabe que lo importante es suspender por un momento la alta emocionalidad, el ámbito familiar, la sensación de que no hay forma de entender lo que está pasando (la incapacidad de representar la crisis). Suspenderlo todo para atender a algo diferente, en colectivo.

El docente tiene un discurso claro: la importancia del vínculo social, de lo común. Ricardo Baquero al referirse al espacio escolar, al escenario áulico señala que "de prescindirse de la creación de un contexto específico -es decir, diferenciado de lo cotidiano- para la enseñanza y aprendizaje, la propia noción de escuela se desplomaría" (BAQUERO, 2020, p. 233). En esa sospecha de la posibilidad de disolución, el maestro convoca a reunirse y ahí se germina una potencialidad de fortalecimiento de los lazos y de simbolización de la dislocación para la reinscripción de nuevos sentidos.

La escuela es uno de los espacios que construye vínculos sociales, en este documento se considera el más importante. La escuela se entiende aquí en consonancia con autores como Simmons y Maschelain y Hannah Arendt, quienes la conceptualizan como un asunto público, común; una institución fundamental para la democracia y un espacio en el que se comparte el mundo (ARENDT, 1977; SIMONS; MASSCHELEIN, 2014).

\footnotetext{
2 - ¿Cómo es ser docente en la pandemia después de haber sido docente presencial? Bien complicado, muy, muy complicado porque si hubo nuevos problemas, desde no tener contacto con los estudiantes. He visto que para mis compañeros con más años ha sido un golpe emocional, extrañan a los compañeros de trabajo, el uso de la tecnología se les dificulta. Otros profes se han rendido y han optado por mandar muchos deberes [...] Puedo compartir que en mi escuela las clases virtuales no fueron la modalidad escogida porque se desconoce la infraestructura tecnológica de los estudiantes, pero abrí un espacio de clases no obligatorias, pensé tanto para mi estudiantes como para mi es importante no perder la cabeza, entonces les pregunté qué tal les parece si nos conectamos, sin obligatoriedad, si es que se pueden conectar se conectan si no pueden no se conectan, yo voy a seguir con las tareas en PFD, por correo, como hemos venido haciendo, pero el que quiera conectarse y pueda hacerlo, va a haber dos horarios, martes y jueves. Los que puedan conectarse leeremos algo, veremos un video, hablaremos al respecto. Era una estrategia para que vivamos no tan mal la pandemia. 3 Flavia Terigi menciona que más de millón y medio de habitantes fueron desplazados hacia el mismo sitio: la virtualidad y emplea esta figura del migrante como metáfora que habilita la extrañeza (TERIGI, 2020).

4 Tejido social es una metáfora para referirse al entramado de relaciones que configuran lo que llamamos realidad social Se trata de procesos históricos de configuración de vínculos sociales e institucionales que favorecen la cohesión y la reproducción de la vida social. En tanto proceso histórico, los lazos o vínculos sociales se van configurado por el accionar de individuos, su relación en colectividades y la incidencia y diálogo con las instituciones que estructuran/organizan (SZTOMPKA, 1995).

5 La dislocación es un quiebre en la capacidad de dar sentido, dentro de la estructura. Es entonces, la interrupción del discurso, la imposibilidad de simbolización dentro del marco de referencia del mismo. Representa el momento de pura eventualidad, puesto que no puede ser contenida por ningún discurso que dé sentido al tiempo. Es el nombre designado a la libertad, ya que constituye el momento de la decisión real (LACLAU, 1997).

6 "La dislocación es constitutiva e irrepresentable en el momento que ocurre, se requiere construir y conocer la respuesta discursiva a la dislocación para poder representarla, por lo tanto, requiere de un tiempo de elaboración” (DE ALBA, 2020, p. 2).
} 
Para profundizar en el sentido de la escuela como espacio vital para constituir lazos sociales, preservar lo común y generar sentidos, "de creación de un mundo nuevo frente al viejo" (ARENDT, 1977, p. 39). Gabriela Diker (2016), expone tres operaciones fundamentales que hacen que una acción se constituya como educativa ${ }^{7}$. Con ellas explica como una acción educativa es subjetiva y política. Esas operaciones dejan ver como la escuela es por excelencia el espacio de construcción de sentidos y vínculos sociales, porque su fin es el mencionado: posibilitar a los nuevos sujetos la concepción de algo nuevo, a partir del conocimiento de la cultura acumulada (DIKER, 2016; ARENDT, 1977).

La escuela logra esto partiendo de un principio de igualdad: todos los niños son iguales en su humanidad liberada en un tiempo-espacio determinado de las diferencias socio-económicas, afectivas, emocionales (SIMONS; MASSCHELEIN, 2014; TERIGI, 2020). Este principio se ve alterado ante la pandemia por COVID 19. Condición que permanece y prevalece y que llevó a la institución escolar a cerrar sus espacios áulicos, a nivel mundial, para ser trasladada a los espacios domésticos en los casos menos afortunados (clases televisadas, por correo electrónico, suspensión de las clases), o a los no lugares virtuales, con presencialidades reunidas en el tiempo y separadas por sus estancias en puntos remotos.

\title{
El currículum como registro y propuesta de la condición social a partir de la Covid-19
}

Después de una dislocación social, que genera nuevas desigualdades y agudiza profundamente las existentes y que, a la vez enfatiza en las posibilidades de comunicación mediadas por la tecnología, es necesario pesar el currículum como medio y registro de las reinscripciones de nuevos sentidos posteriores a la pandemia, como lo plantea Tomás Tadeu Da Silva (1998, p. 70):

\begin{abstract}
El currículum visto como producto acabado, concluido, no puede dejar de revelar las marcas de las relaciones sociales de su producción. Desde su génesis como macrotexto de política curricular hasta su transformación en microtexto en el aula, pasando por sus diversos avatares intermediarios (guías, directrices, libros didácticos), en el currículum van quedando registrados los restos de las disputas por el predominio cultural, las negociaciones en torno a las representaciones de los diferentes grupos y las diferentes tradiciones culturales, de las luchas entre los saberes oficiales y dominantes por un lado, y los saberes subordinados, relegados y despreciados por el otro. Esas marcas no dejan olvidar que el currículum es relación social.
\end{abstract}

Para Ernesto Laclau "hay política cuando hay, por un lado, dislocación, y del otro lado, reinscripción, es decir, espacialización o hegemonización de esa dislocación” (LACLAU, 1997, p. 140). El currículum actualizado, la escuela potencializada en su acepción de espacio de garantía del tiempo libre, de lo protección de lo público, de construcción de subjetividades enlazadas en un tejido común es una enérgica herramienta de reinscripción. La escuela y el currículum no son los escenarios o documentos donde se refleja la cultura sino son los espacios por excelencia de construcción de sentidos (TERIGI, 2016).

Prácticas concretas como la del docente citado al inicio de este texto demuestra que a partir de la dislocación el sujeto tiene un instante, un guiño de libertad que se le presenta para construir un nuevo sentido en el derrotero de poner al centro significados, narrativas, herramientas que contribuyan a la labor de la institución escolar en el mejoramiento de la sociedad. Para hacer abrir posibilidades a partir de habitar en la cuarentena los efectos de una sociedad global regida un

71. Transmitir, distribuir un "fondo cultural común" de conocimientos, saberes, valores, reglas, etc. 2. Orientar o ayudar a sacar algo que alguien ya tiene. 3. Hacer algo con alguien, de alguien o, en términos de Antelo (2005), intervenir, "meterse" con el otro. Meirieu (2001). (DIKER, 2016). 
orden vaciado de responsabilidad con los otros, de un ambiente natural y social desequilibrado por acciones carentes de una perspectiva del bien común.

El profesor citado encontró una puerta para generar nuevas narrativas, preguntas y sentidos que deben ser puestos a la vista, al igual que otras prácticas específicas como esa, pensando en fortalecer la escuela y mejorar las condiciones de ejercicio de la docencia que, en futuro cercano, volverá a sus espacios áulicos, siendo seguramente todos (niños, padres, maestros, etc.), diferentes en algo.

\section{Consideraciones finales: para pensar el currículum a los docentes y a los estudiantes}

En una de las entrevistas, el docente volvió al asunto de la no obligatoriedad de la actividad propuesta para hablar sobre cómo cada semana hay menos estudiantes en su escuela, debido a que se ven arrojados del sistema educativo debido a la falta de infraestructura tecnológica. En la región latinoamericana el porcentaje de deserción a razón del confinamiento es de una tasa de más del quince por ciento. Los niños y jóvenes no tienen computadores, internet, un espacio dentro de casa para destinar a los estudios, acompañamiento, en muchos casos la alimentación no está garantizada. Es necesario remarcar que nunca ha existido una completa garantía al derecho a la educación, hay crisis que están siendo invisibilizadas por La Crisis de la Covid. Y ahora se suman las niñas y niños y adolescentes a quienes no se ha garantizado la infraestructura necesaria hasta palear la crisis y reabrir las aulas. Que la escuela no se haya detenido del todo no garantiza que todos estén incluidos.

En segundo lugar, se considera importante poner a discusión para el futuro del currículum el refuerzo de la educación ambiental; el énfasis en el arte como máxima expresión de la libertad y de lo público; hacer hincapié en todos los contenidos que permitan entender de manera más amplia la comprensión de los otros, de la pluralidad de formas de pensar, sentir, habitar la vida. En búsqueda de erradicar estereotipos, prejuicios y odio, y que el sentido común sea el bien social. Algunas posibilidades para ello pueden ser: el estudio de las religiones y formas de espiritualidad, no solo las grandes religiones del mundo si no las formas de religiosidad de las diversas culturas originarias de los países de América. Además, es importante retomar los saberes denostados por el predominio de la lógica cientificista para caminar a una justicia epistémica. Por ejemplo, los desvalorizados labores manuales $\mathrm{u}$ oficios, que hacen posible comprender que son necesarias muchas personas para crear un objeto, el vínculo del sujeto con el mismo, el tiempo y el proceso y procedencia de los materiales.

No se hace alusión a la enseñanza de una actividad manual con la intención de educar especialistas en un oficio, sino como una tecnología pedagógica que permita comprender valores sociales, ambientales, ciudadanos ${ }^{8}$, como una forma diferente de relacionamiento con el tiempo y el territorio. También, y entendiendo que los medios de comunicación y las redes sociales realizan operaciones pedagógicas ${ }^{9}$, es importante incluir contenidos que permitan una comprensión crítica de los relatos y discursos que allí se generan. Es necesario contemplar las vías de comunicación de las generaciones actuales para disminuir las brechas intergeneracionales $\mathrm{y}$, al contrario, tender puentes de dialogo, de comprensión. La diversidad etaria es parte de la pluralidad.

\footnotetext{
8 Esta reflexión fue planteada por la doctora Ana María SALMERÓN en el seminario de Justicia Educativa, en el posgrado de Pedagogía de UNAM (SALMERÓN, 2020-2021).

9 La operación pedagógica es una categoría de la académica mexicana Alicia de Alba quien señala que es una interpelación que al generar una identificación produce subjetividades porque es la invitación a un proyecto de vida, familiar, comunitario, regional, nacional y mundial, se hace desde un espacio cronotrópico; esto es, situado en el tiempo, en el espacio, en formas de ser, de vivir, de percibir, de sentir, de inscribirse en la naturaleza (DE ALBA, 2020, p. 4).
} 
Finalmente, la narración del docente entrevistado pone también en evidencia una problemática que hace mucho tiempo se denuncia: la aniquilación de la docencia a partir de la domesticación del profesor $^{10,11}$ a través de la carga de tareas que no le corresponden y que anulan su tiempo y energía de dedicación a la disciplina que enseña y a los estudiantes. Finalmente, es pertinente acentuar que este texto se une a las voces que sostienen que la escuela es imprescindible y que no hay que cambiarla por ordenadores una vez superada la pandemia. La infancia necesita la escuela como ese Espacio otro, alterno al hogar. Ese espacio común, de compartires, de igualdad, de conocimiento. Ese escenario donde es posible mirar una parte del mundo e interesarse en él:

Prefiero el aula, el contacto con la gente, ver a los chicos, reírme con ellos. Jugar básquet con ellos, sacarme la camisa, ponerme una camiseta y lanzarme a la cancha con ellos. Extraño ese tiempo divertido, feliz, alegre. La escuela es también un escape para los chicos, de los muchos problemas que tienen. $\mathrm{Si}$, era genial ver que por lo menos en el colegio podían chismear con sus amigos. ¡Mil veces prefiero lo presencial!.

\section{Referências}

ARENDT, Hannah. La crisis de la educación. Cuaderno gris, Espanha, n. 7, p. 38-53,1977.

BAQUERO, Ricardo. La torsión del espacio escolar. In: DUSEL, Inés; FERRANTE, Patricia; PULFER, Darío. Pensar la educación en tiempos de pandemia: entre la emergencia, el compromiso y la espera. Ciudad Autónoma de Buenos Aires: UNIPE, 2020. p. 231-243.

BOLÍVAR, Antonio. ¿De nobis ipsis silemus?: epistemología de la investigación biográfico-narrativa en la educación. Revista electrónica de investigación educativa, México, v. 4, n. 1, p. 1-26, mayo 2002.

DA SILVA, Tomas Tadeu. Cultura y currículum como prácticas de significación. Revista de Estudios del Currículum, Barcelona, v. 1, n.1, p. 59-76, 1998.

DE ALBA, Alicia. Curriculum universitario, sociedad y pandemia. ¿Nos encontramos en la construcción de una nueva narración constitutiva? In: COLOQUIO LA UNIVERSIDAD Y SU FUTURO, 2020, Ciudad de México. Anais [...]. Ciudad de México: Secretaria General: IISUE-UNAM, 2020.

DIKER, Gabriela. Educación. In: SALMERÓN, Ana María; TRUJILLO REYES, Blanca Flor; DEL HUERTO RODRÍGUEZ, Azucena; DE LA TORRE GAMBOA, Miguel. Diccionario Iberoamericano de filosofía de la Educación. [S. l.]: Fondo Económico de Cultura: FFyL: UNAM, 2016.

LACLAU, Ernesto. Hegemonía y antagonismo: el imposible fin de lo político. Santiago de Chile: Cuarto propio, 1997.

SANTOS, Boaventura de Soussa. La cruel pedagogía del virus. Buenos Aires: Clacso, 2020.

SALMERÓN, Ana María. Seminario de Justicia Educativa. Ciudad de México: UNAM, 2020-2021.

SIMONS, Maarten; MASSCHELEIN, Jan. En defensa de la escuela. Madrid: Miño y Dávila, 2014.

SZTOMPKA, Piotr. Sociología del cambio social. Madrid: Alianza, 1995.

10 Simons y Masschelein (2014) exponen sobre la domesticación del profesor en "En defensa de la escuela".

11 Fragmento de entrevista -Me gustaría saber si el trabajo en casa, en virtualidad ha tenido algún aspecto positivo para ti. -Si, yo me logré preparar más a nivel profesional, porque había demasiadas cosas por hacer en la escuela sumadas a la movilización y no tenía tiempo y eso me llevaba a leer menos, a planificar menos y en este tiempo de pandemia he podido volver a las lecturas pendientes, planificar más las clases, pensar más en ello, dedicarme a pensarlo a hacerlo de diferentes maneras. La pandemia ha sido un sacudón para pensar y crear cosas buenas, como profe estoy preparando más cosas para que los chicos se interesen más por lo que les presento a pesar del distanciamiento, busco plataformas geniales, páginas, videos, ya no tienen que imprimir. 
TERIGI, Flavia. Aprendizaje en el hogar comandado por la escuela: cuestiones de descontextualización y sentido. In: FERRANTE, Patricia; DUSSEL, Inés; DARÍO, Pulfer. Pensar la educación en tiempos de pandemia: Entre la emergencia, el compromiso y la espera. Ciudad Autónoma de Buenos Aires: UNIPE, 2020. p. 443-251.

TERIGI, Flavia. Currículum. In: SALMERÓN, Ana María; TRUJILLO, Blanca Flor; DEL HURTO RODRÍGUEZ OUSSET, Azucena; DE LA TORRE GAMBOA, Miguel. Diccionario Iberoamericano de Educación. [S. l.]: Fondo Económico de Cultura: FFyL: UNAM, 2016. Disponible en: https://fondodeculturaeconomica.com/dife/definicion. aspx?l=C\&id=47. Acceso en: 12 dic. 2020.

Data de submissão: 02/02/2021

Data de aceite: $22 / 03 / 2021$ 